\title{
Cost-effectiveness of 7-day-Holter monitoring alone or in combination with transthoracic echocardiography in patients with cerebral ischemia
}

\author{
Felix Mayer $\cdot$ Raoul Stahrenberg $\cdot$ Klaus Gröschel $\cdot$ Sarah Mostardt $\cdot$ \\ Janine Biermann · Frank Edelmann · Jan Liman · Jürgen Wasem • \\ Alexander Goehler $\cdot$ Rolf Wachter $\cdot$ Anja Neumann
}

Received: 14 June 2013/Accepted: 17 July 2013/Published online: 2 August 2013

(C) The Author(s) 2013. This article is published with open access at Springerlink.com

\begin{abstract}
Background and purpose Prolonged Holter monitoring of patients with cerebral ischemia increases the detection rate of paroxysmal atrial fibrillation (PAF); this leads to improved antithrombotic regimens aimed at preventing recurrent ischemic strokes. The aim of this study was to compare a 7-day-Holter monitoring (7-d-Holter) alone or in combination with prior selection via transthoracic echocardiography (TTE) to a standard 24-h-Holter using a cost-utility analysis. Methods Lifetime cost, quality-adjusted life years (QALY), and incremental cost-effectiveness ratios (ICER) were estimated for a cohort of patients with acute cerebral ischemia and no contraindication to oral anticoagulation. A Markov model was developed to simulate the long-term course and progression of cerebral ischemia considering
\end{abstract}

F. Mayer and R. Stahrenberg contributed equally and share first authorship. R. Wachter and A. Neumann share last authorship.

F. Mayer $\cdot$ S. Mostardt $\cdot$ J. Biermann $\cdot$ J. Wasem .

A. Goehler · A. Neumann $(\bowtie)$

Institute for Health Care Management and Research,

University of Duisburg-Essen, Campus Essen, Schützenbahn 70,

45127 Essen, Germany

e-mail: anja.neumann@medman.uni-due.de

F. Mayer

e-mail: fel_mayer@web.de

R. Stahrenberg · F. Edelmann · R. Wachter

Department of Cardiology and Pneumology,

University of Göttingen, Göttingen, Germany

K. Gröschel · J. Liman

Department of Neurology, University of Göttingen,

Göttingen, Germany

K. Gröschel

Department of Neurology, University of Mainz,

Mainz, Germany the different diagnostic algorithms (24-h-Holter, 7-d-Holter, 7-d-Holter after preselection by TTE). Clinical data for these algorithms were derived from the prospective observational Find-AF study (ISRCTN 46104198).

Results Predicted lifelong discounted costs were $33,837 €$ for patients diagnosed by the 7-d-Holter and 33,852 $€$ by the standard 24-h-Holter. Cumulated QALYs were 3.868 for the 7-d-Holter compared to 3.844 for the 24 -h-Holter. The 7-d-Holter dominated the 24-h-Holter in the base-case scenario and remained cost-effective in extensive sensitivity analysis of key input parameter with a maximum of $8,354 € /$ QALY gained. Preselecting patients for the 7-dHolter had no positive effect on the cost-effectiveness.

Conclusions A 7-d-Holter to detect PAF in patients with cerebral ischemia is cost-effective. It increases the detection which leads to improved antithrombotic regimens; therefore, it avoids recurrent strokes, saves future costs,

\section{F. Edelmann · R. Wachter}

German Cardiovascular Research Center,

Göttingen, Germany

A. Goehler

Medical Informatics and Technology, University for Health Sciences, Hall, Austria

A. Goehler

Cardiac MR PET CT Program and Institute for Technology

Assessment, Department of Radiology, Massachusetts General

Hospital, Harvard Medical School, Boston, USA 
and decreases quality of life impairment. Preselecting patients by TTE does not improve cost-effectiveness.

Keywords Atrial fibrillation $\cdot$ Stroke $\cdot$ Holter monitoring $\cdot$ Cost-effectiveness $\cdot$ Markov model

\section{Introduction}

Stroke poses a heavy economic burden, accounting for $\sim 2$ to $7 \%$ of total health expenditures that is equivalent to $0.15-0.36 \%$ of the gross domestic product of western societies [1-3]. Atrial fibrillation (AF) is a frequent cause of ischemic stroke (IS) [4] and patients with AF have an almost fivefold increased risk of suffering a second stroke $[5,6]$. Better detection of paroxysmal atrial fibrillation (PAF) by prolonged Holter monitoring [7] can be expected to improve secondary prevention through optimized secondary preventive regimens, namely, oral anticoagulation for those with PAF [8-10]. However, 7-day-Holter monitoring (7-d-Holter) is associated with increased costs. We therefore proposed to select patients with a high pre-test probability for PAF for extended Holter monitoring by applying a recently described index of left atrial enlargement and impaired left atrial function as measured by transthoracic echocardiography [11]. We aimed to evaluate the cost-effectiveness of three diagnostic strategies to detect PAF after acute cerebral ischemia: (a) standard 24-h-Holter monitoring (24-h-Holter), (b) 7-d-Holter, or (c) 7-d-Holter in a subgroup only, preselected by TTE (TTE/7-d-Holter).

\section{Methods}

Study population

The Markov model considers a hypothetical cohort of patients after the first ever IS or transient ischemic attack (TIA) presenting in sinus rhythm. In this cohort, AF has not previously been diagnosed and no contraindication of OAC therapy exists. The mean age is 68 years. Further details on the FIND-AF (ISRCTN 46104198) trial and its study population have been published elsewhere [7].

Model structure and health states

We developed a Markov microsimulation model to estimate lifetime costs, cumulative quality-adjusted life years (QALYs), and the incremental cost-effectiveness ratio (ICER) of alternative diagnostic algorithms using TreeAge Pro Suite 2009 (TreeAge Software, Inc., Williamstown, Massachusetts). Markov modeling is a suitable technique in decision problems that involve risks and costs that can recur and/or change over time [12]. Our model analysis considered a lifelong horizon and we chose a cycle length of 6 months. The simulation was ended once the fraction of the cohort remaining alive fell below a threshold of $1 \%$. Costs of care were estimated from a third party payers' perspective. Costs and quality of life estimates were discounted at a rate of $3 \%$ [12]. After screening for PAF using 24-h-Holter, 7-d-Holter or TTE/7-d-Holter, patients entered a Markov model that simulated the long-term disease course and progression of cerebral ischemia, adverse events such as recurrent ISs, intracranial hemorrhage (ICH) or fatal strokes as well as dying from other causes. The risk of IS recurrence and ICH depended on the patient's age and anticoagulation regimen. Our simulation model distinguished between seven permanent health states, namely TIA, minor stroke, major stroke, recurrent minor or major stroke, ICH and death. The general model structure and possible transitions between permanent health states are depicted in Figs. 1 and 2.

Transthoracic echocardiography and detection rates of Holter monitoring

Our model compares three diagnostic algorithms/strategies to detect PAF. These strategies differed in detection rates of PAF, as derived from the FIND-AF cohort (Table 1). Prevalence of detected PAF was $13.3 \%$ for 7-d-Holter [11]. Within our comparative approach, we considered 7-dHolter to have $100 \%$ sensitivity for PAF. The 24-h-Holter only detected PAF in $46.4 \%$ of the patients who were positive using 7-d-Holter, leaving $53.6 \%$ of the PAF cases undetected [7]. After preselecting patients for the 7-dHolter using TTE $(51.1 \%$ of all patients had LAVI/ $\mathrm{a}^{\prime}>2.3$ and therefore qualified for 7-d-Holter), the prevalence of PAF detected by 7-d-Holter was $23.9 \%$. Using the cut-off value of LAVI/a $\mathrm{a}^{\prime} \leq 2.3$ as measured by TTE yielded $2.2 \%$ of false negatives in FIND-AF [11]. The model considers patients receiving oral anticoagulation in form of warfarin or aspirin (ASS) as the most commonly used antiplatelet [13]. When PAF was detected by the 24-hHolter or the 7-d-Holter, the treatment regimen was changed to warfarin, while all PAF-negative patients are treated with ASS (Fig. 1).

Probability of adverse outcomes

To obtain key model inputs for IS/TIA recurrence, we reviewed relevant clinical trials and meta-analyses that investigated warfarin and aspirin therapy for secondary stroke prevention in patients with AF: $6.3 \%$ annual rate of IS/TIA on ASS (false-negative detection) and a 0.48 relative risk of IS/TIA with warfarin compared to ASS resulting in $3.02 \%$ annual rate on warfarin $[14,15]$. Furthermore, we modeled a 4.8 relative risk of recurrent 


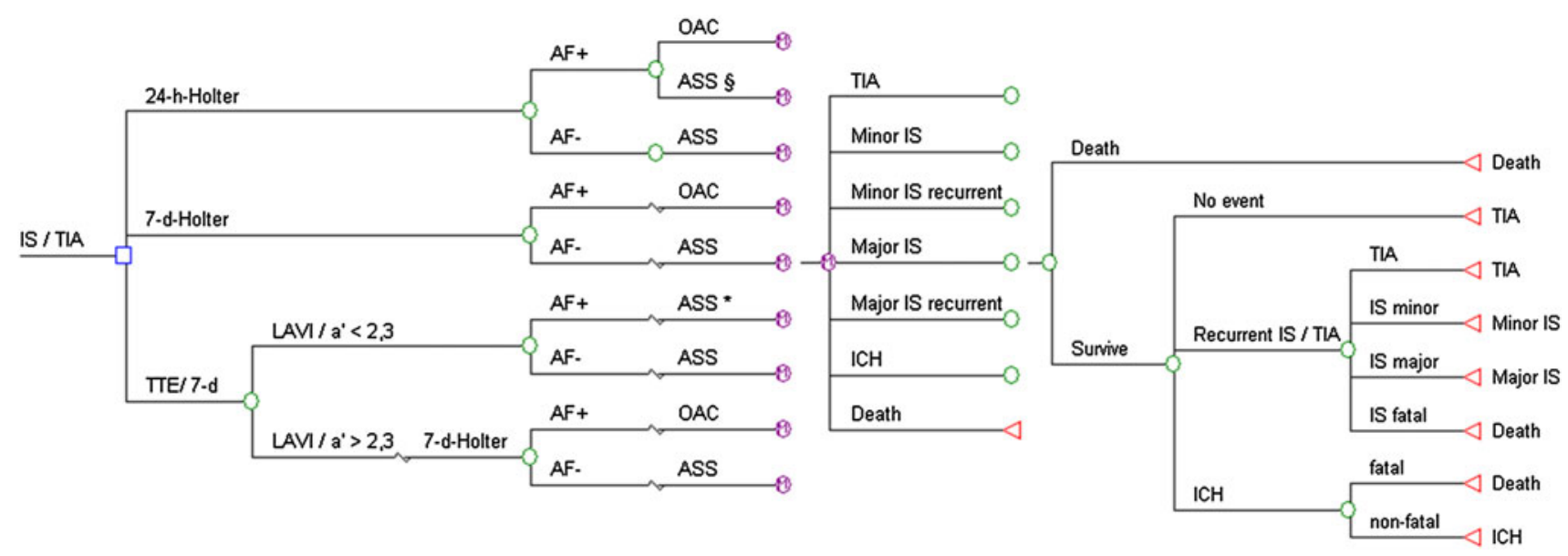

Fig. 1 Decision model. It considers three diagnostic algorithms: 24-h-Holter monitoring referred to as standard diagnostic, 7-d-Holter and 7-d-Holter preceded by transthoracic echocardiography (TTE). Section displays false-negative results of 24-h-Holter and asterisk indicates false-negative results of TTE and, therefore, patients falsely treated with antiplatelets only. $A F+/ A F-$ patients with/without atrial fibrillation as a result of the three diagnostic algorithms, ASS aspirin, $I C H$ intracranial hemorrhage, IS ischemic stroke, LAVI left atrial volume index, OAC oral anticoagulation, TIA transient ischemic attack, TTE transthoracic echocardiography

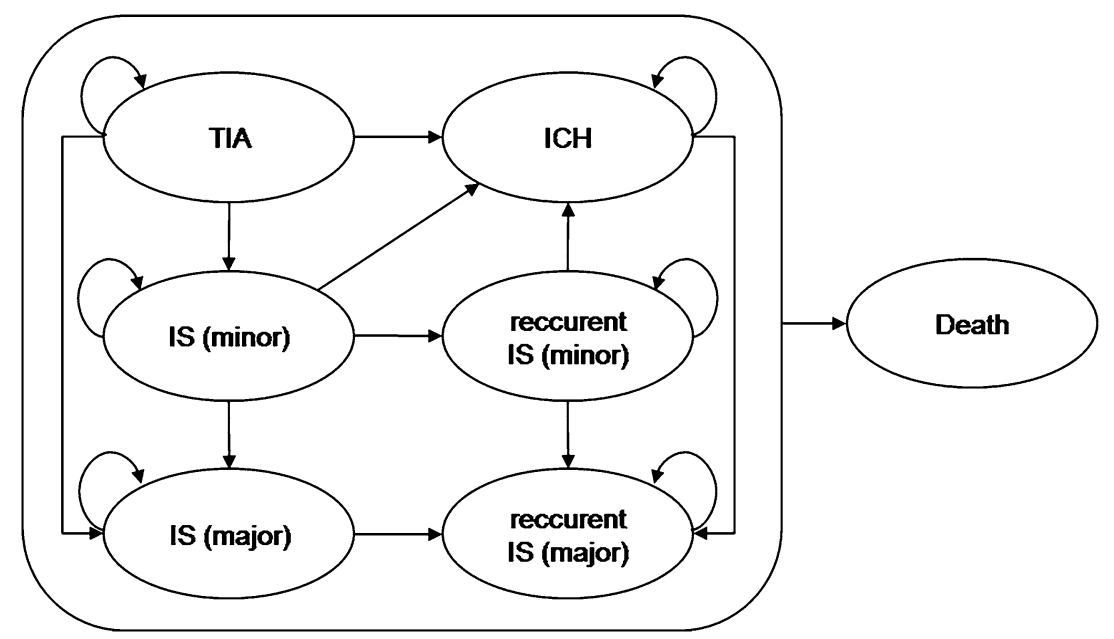

Fig. 2 Possible transitions between permanent health states. Based on stroke severity within the FIND-AF cohort, patients start in one of the defined states namely TIA, minor stroke, major stroke, and recurrent minor or major stroke. Then patients cycle between states

IS/TIA for patients with PAF compared to PAF-negative patients resulting in an annual recurrence rate of $1.31 \%$ for PAF-negative patients treated with ASS [6, 14]. Annual rates for IS/TIA were increased by a factor of 1.4 per decade of life (multiplicative adjustment) to account for increasing age [16]. To account for different stroke severity levels, we classified IS into four categories: TIA, minor stroke, major stroke, and fatal stroke [17]. We considered an annual rate hemorrhagic stroke/intracranial hemorrhage of $1.28 \%$ for warfarin and $0.76 \%$ for aspirin (relative risk ASS vs. warfarin: 0.59) $[15,18]$. Hemorrhage-related event rates were increased by a factor of 1.97 per decade of life until death. The cycle length is 6 months. A transition to death from any cause (background mortality or fatal strokes) is possible from any state. ICH intracranial hemorrhage, IS ischemic stroke, TIA transient ischemic attack

(crude relative risk for every 10-year increase in age) [19]. Similarly to our consideration of different IS levels, we classified ICH into fatal and non-fatal events with a basecase mortality of OAC-associated ICH of $60 \%$ [20]. Table 1 depicts all variables used in detail.

\section{Background mortality}

Background mortality was modeled using age specific mortality rates adjusted for the increased risk of dying after cerebral ischemia [21]. These values reflect 6-month event rates after the initial event (Table 1) [22]. 
Table 1 Model variables: base case and range used in sensitivity analysis

\begin{tabular}{|c|c|c|c|}
\hline Input variables & Base case & Range & References \\
\hline \multicolumn{4}{|l|}{ Atrial fibrillation-detection parameters ${ }^{\mathrm{a}}(\%)$} \\
\hline Proportion of patients with LAVI/a ${ }^{\prime} \leq 2.3$ & 48.9 & $(44.01-53.79)$ & {$[11,7],[$ FIND-AF] } \\
\hline Proportion of patients with LAVI $/ \mathrm{a}^{\prime}>2.3$ & 51.1 & $(45.99-56.21)$ & {$[11,7],[$ FIND-AF] } \\
\hline Negative predictive value $\left(\mathrm{LAVI} / \mathrm{a}^{\prime} \leq 2.3\right)$ & 97.8 & $(88.02-100.0)$ & {$[11,7],[$ FIND-AF] } \\
\hline False negatives $\left(\mathrm{LAVI} / \mathrm{a}^{\prime} \leq 2.3\right)$ & 2.2 & $(1.98-2.42)$ & {$[11,7],[$ FIND-AF] } \\
\hline Prevalence of AF (no preceding TTE) & 13.3 & $(11.97-14.63)$ & {$[11,7],[$ FIND-AF] } \\
\hline Prevalence of AF after preceding TTE & 23.9 & $(21.51-26.29)$ & {$[11,7],[$ FIND-AF] } \\
\hline Sensitivity of 24-h-Holter & 46.4 & $(41.76-51.04)$ & {$[11,7],[$ FIND-AF] } \\
\hline False negatives (24-h-Holter) & 53.6 & {$[48.24-58.96]$} & {$[11,7],[$ FIND-AF] } \\
\hline \multicolumn{4}{|l|}{ Ischemic stroke parameters } \\
\hline Annual rate of stroke with warfarin and $\mathrm{AF}^{\mathrm{a}, \mathrm{b}}(\%)$ & 3.02 & $(2.72-3.32)$ & {$[14,15]$} \\
\hline \multicolumn{4}{|l|}{ Ischemic strokes with warfarin that were } \\
\hline Fatal $(\%)$ & 8.2 & $(8.2-10.1)$ & {$[17]$} \\
\hline Major (disabling) (\%) & 40.2 & $(40.2-41.7)$ & {$[17]$} \\
\hline Minor $(\%)$ & 42.5 & $(34.8-42.5)$ & {$[17]$} \\
\hline TIA/no residua $(\%)$ & 9.1 & $(9.1-13.3)$ & {$[17]$} \\
\hline Relative risk of stroke with warfarin compared with aspirin & 0.48 & $(0.37-0.63)$ & {$[15]$} \\
\hline Annual rate of stroke with aspirin and $\mathrm{AF}^{\mathrm{b}}(\%)$ & 6.3 & $(5.67-6.93)$ & {$[14]$} \\
\hline Relative risk of stroke with $\mathrm{AF}$ compared to without $\mathrm{AF}$ & 4.8 & $(2.0-6.0)$ & {$[6]$} \\
\hline Annual rate of stroke with aspirin and without $\mathrm{AF}^{\mathrm{b}}(\%)$ & 1.31 & $(1.18-1.44)$ & {$[6,14]$} \\
\hline \multicolumn{4}{|l|}{ Ischemic strokes with aspirin that were: } \\
\hline Fatal $(\%)$ & 17.9 & $(10.1-17.9)$ & [17] \\
\hline Major (disabling) (\%) & 30.0 & $(30.0-41.7)$ & {$[17]$} \\
\hline Minor $(\%)$ & 41.0 & $(34.8-41.0)$ & {$[17]$} \\
\hline TIA/no residua $(\%)$ & 11.0 & $(11.0-13.3)$ & [17] \\
\hline \multicolumn{4}{|l|}{ Hemorrhagic stroke parameters } \\
\hline Annual rate of hemorrhagic stroke/ICH with warfarin ${ }^{\mathrm{a}, \mathrm{c}}(\%)$ & 1.28 & $(1.15-1.41)$ & {$[18]$} \\
\hline Relative risk of hemorrhage with aspirin compared with warfarin & 0.59 & $(0.5-0.7)$ & {$[15]$} \\
\hline Annual rate of hemorrhagic stroke/ICH with aspirin ${ }^{\mathrm{c}}(\%)$ & 0.76 & $(0.68-0.84)$ & {$[15,18]$} \\
\hline Mortality after hemorrhagic stroke/ICH & 0.6 & $(0.46-0.68)$ & {$[20]$} \\
\hline \multicolumn{4}{|l|}{ Mortality parameters, excluding acute stroke $\mathrm{e}^{\mathrm{a}, \mathrm{d}}$} \\
\hline Months $0-6(\%)$ & 10.24 & $(9.22-11.26)$ & {$[21]$} \\
\hline Months 6-12 (\%) & 6.20 & $(5.58-6.82)$ & {$[21]$} \\
\hline Year 2-5 after stroke $(\%)$ & 2.96 & $(2.66-3.26)$ & {$[21]$} \\
\hline Year 6-15 after stroke (\%) & 6.76 & $(6.08-7.44)$ & {$[21]$} \\
\hline Year $16+$ after stroke $(\%)$ & 9.15 & $(8.23-10.06)$ & {$[21]$} \\
\hline \multicolumn{4}{|l|}{ Quality of life estimates ${ }^{\mathrm{a}}$} \\
\hline Ischemic stroke/major & 0.52 & $(0.47-0.57)$ & {$[32]$} \\
\hline Ischemic stroke/minor & 0.87 & $(0.78-0.96)$ & {$[32]$} \\
\hline Recurrent stroke (2nd disabling stroke) & 0.12 & $(0.11-0.13)$ & {$[31]$} \\
\hline TIA & 0.9 & $(0.81-0.99)$ & {$[33]$} \\
\hline Hemorrhagic stroke/intracranial hemorrhage (ICH) & 0.62 & $(0.55-0.67)$ & [34] \\
\hline
\end{tabular}

$A F$ atrial fibrillation, ICH intracranial hemorrhage, $L A V I$ left atrial volume index, TTE transthoracic echocardiography TIA transient ischemic attack

${ }^{\text {a }}$ Range $\pm 10 \%$

${ }^{\mathrm{b}}$ Rate of stroke increased by the factor 1.4 per decade of life, compounded for every 6-month cycle

${ }^{c}$ Rate of hemorrhagic stroke/ICH increased by the factor 1.97 per decade of life, compounded for every 6-month cycle

${ }^{d}$ Mortality parameters adapted to a cycle length of 6 months 


\section{Costs estimates}

Since Find-AF was conducted in Germany, direct costs were estimated in a way such that it reflected the German health care system, i.e., DRG rate payments for hospitalization. All costs were adjusted to 2011 Euro using German consumer price indices.

\section{Acute care}

Costs of acute care after recurrent events include those for emergency ambulance transportation, hospitalization, and inpatient (acute) rehabilitation (Table 2). Cost data which could not be extracted from the literature such as direct costs for acute hospitalization of patients with TIA were calculated using a nationwide base-rate of 2,936 $€$ and a relative (cost) weight based on the appropriate DRG (B69) taken from the institute for the hospital remuneration system (InEK Begleitforschung) in Germany [23, 24]. The base rate was calculated by weighting the base rates of all German federal states (Verband der Ersatzkassen e. V.) by their total case mix as published by the InEK. Costs of acute hospitalization in patients with hemorrhagic strokes were calculated using a web DRG grouper based on the appropriate ICD as recommended by the German coding guidelines for neurological diseases (ICD I61, I69.1 und D68.30) and the nationwide base-rate [25, 26].

\section{Post-acute care}

For every subsequent 6-month cycle after cerebral ischemia we included costs for emergency ambulance transportation, hospitalization, outpatient care, medication, rehabilitation, reintegration, and nursing care (Table 3). Regarding post-acute costs of care, we distinguished between costs that occurred during the months 1-6, 7-12 and every following 6 months period after the initial event [27]. Calculation of medication costs was restrained to the different anticoagulation regimens under the assumption that medications for patients with PAF differ from those without PAF in the antithrombotic regimen only, by using the appropriate costs per defined daily dose (DDD) as published in the Arzneimittelverordnungsreport 2010 and adjusted these costs to reflect our cycle length [28]. INR measurements were not calculated separately, since they were included in the costs of outpatient care as reported by Brüggenjürgen et al. [27]. Post-acute costs varied by different health states and were considered every 6-month period after the initial event (Table 3 ). We assumed that rehabilitation, reintegration, and permanent nursing care were not necessary in patients who were not permanently compromised, and thus, did not include these costs in our analysis. Post-acute costs for TIA patients were limited to the costs of both anticoagulation regimens. Since there was limited data available considering post-acute costs of patients after $\mathrm{ICH}$, we calculated these costs based on the relative difference in the utilities for patients after major IS and $\mathrm{ICH}$ (cost reduction $19.23 \%$ ).

\section{Resource costs of prolonged Holter monitoring}

For the last 21 patients who had received the 7-d-Holter in Find-AF, detailed data on resource utilization were collected and compared to the 24-h-Holter. Based on these data, additional costs were added once for every patient in the 7-d-Holter strategy and those patients who received 7-d-Holter in the TTE/7-d-Holter strategy. To estimate costs for medical staff, costs per minute were calculated according to the gross annual salary and mean annual working time of medical practitioners and medical technical assistants in Germany [29, 30]. Preceding TTE was considered to be a standard procedure for patients with

Table 2 Cost variables for acute treatment: base case and range used in sensitivity analysis

\begin{tabular}{|c|c|c|c|}
\hline Input variables & Base case & Range & References \\
\hline \multicolumn{4}{|l|}{ Cost of acute care ${ }^{\mathrm{a}, \mathrm{b}}(€)$} \\
\hline Ischemic stroke (with AF) & 7,315 & $(6,584-8,047)$ & {$[27,42]$} \\
\hline Ischemic stroke (without $\mathrm{AF}$ ) & 6,224 & $(5,602-6,846)$ & {$[27,42]$} \\
\hline Ischemic stroke (fatal) & 4,031 & $(3,628-4,434)$ & [43] \\
\hline Hemorrhagic stroke & 5,546 & $(4,991-6,100)$ & {$[23,25-27]$} \\
\hline Hemorrhagic stroke (fatal) & 3,652 & $(3,287-4,017)$ & [43] \\
\hline Transient ischemic attack (TIA) & 2,637 & $(2,373-2,900)$ & {$[24,27]$} \\
\hline Additional resource cost 7-d vs. 24-h-Holter ${ }^{\mathrm{a}}(€)$ & 34 & $(20-165)$ & [FIND-AF], [29] \\
\hline Cost discounting rate $(\%)$ & 3 & {$[1-5]$} & {$[12]$} \\
\hline
\end{tabular}

$A F$ atrial fibrillation, TIA transient ischemic attack

${ }^{a}$ Presented in 2011 Euros

b Range $\pm 10 \%$ 
Table 3 Cost variables: base case and range used in sensitivity analysis

\begin{tabular}{|c|c|c|c|c|c|c|c|}
\hline \multirow[t]{2}{*}{ Post-acute cost of care ${ }^{\mathrm{a}, \mathrm{b}}(€)$} & \multicolumn{2}{|c|}{ Month 1-6 after event } & \multicolumn{2}{|c|}{ Month 7-12 after event } & \multicolumn{2}{|c|}{$\begin{array}{l}\text { Every following 6-month period } \\
\text { after year } 1\end{array}$} & \multirow[t]{2}{*}{ References } \\
\hline & Base case & Range & Base case & Range & Base case & Range & \\
\hline Ischemic stroke (major, aspirin) & 7,224 & $(6,503-7,948)$ & 6,420 & $(5,778-7,062)$ & 5,635 & $(5,072-6,199)$ & {$[27,28]$} \\
\hline Ischemic stroke (major, warfarin) & 7,265 & $(6,534-7,986)$ & 6,460 & $(5,809-7,099)$ & 5,674 & $(5,102-6,236)$ & {$[27,28]$} \\
\hline Ischemic stroke (minor, aspirin) & 2,075 & $(1,868-2,283)$ & 1,599 & $(1,439-1,759)$ & 1,123 & $(1.011-1.235)$ & {$[27,28]$} \\
\hline Ischemic stroke (minor, warfarin) & 2,115 & $(1,899-2,321)$ & 1,639 & $(1,470-1,796)$ & 1,163 & $(1,042-1,274)$ & {$[27,28]$} \\
\hline Hemorrhagic stroke (aspirin) & 5,837 & $(5,252-6,420)$ & 5,186 & $(4,667-5,704)$ & 4,551 & $(4,096-5,006)$ & {$[27,28]$} \\
\hline Hemorrhagic stroke (warfarin) & 5,871 & $(5,278-6,450)$ & 5,220 & $(4,692-5,734)$ & 4,585 & $(4,121-5,037)$ & {$[27,28]$} \\
\hline TIA (aspirin) & 8 & $(7.2-8.8)$ & 8 & $(7.2-8.8)$ & 8 & $(7.2-8.8)$ & [28] \\
\hline TIA (warfarin) & 42 & $(37.8-46.2)$ & 42 & $(37.8-46.2)$ & 42 & $(37.8-46.2)$ & {$[28]$} \\
\hline
\end{tabular}

TIA transient ischemic attack

a Presented in 2011 Euros, differentiated by stroke severity and anticoagulation regimen

b Range $\pm 10 \%$

acute cerebral ischemia during hospitalization resulting in no additional costs (Table 2).

Quality of life estimates

To calculate the quality-adjusted survival, literature search was done to obtain suitable quality of life estimates (utilities) for each health state modeled (Table 1) [17, 31]. For major stroke, the mean utility was 0.52 and 0.87 for minor stroke [32]. For recurrent disabling strokes-i.e., a second major stroke or a major stroke following $\mathrm{ICH}$-we used a mean utility of 0.12 [31]. For patients after TIA we used a utility of 0.9 and for ICH $0.62[33,34]$. The utility of death from any cause was 0 . Patients remained in their original state when a recurrent event was less severe (e.g., TIA in patients with previous major stroke).

Sensitivity analyses

We performed sensitivity analyses for all variables used in the model. Where no data about the plausible range of the input variable were available it was varied $\pm 10 \%$.

\section{Results}

Base-case analysis

In the base-case scenario, the discounted quality-adjusted life expectancy in a 68-year-old patient with acute IS or TIA ranged from 3.833 QALYs for patients with 24-h-Holter to 3.842 QALYs with TTE/7-d-Holter and 3.844 QALYs with 7-d-Holter. Mean discounted lifetime costs ranged from $32,887 €$ for the TTE/7-d-Holter to $32,912 €$ for the $24-\mathrm{h}$ Holter (Table 4); 24-h-Holter was dominated by 7-d-Holter and TTE/7-d-Holter, respectively. The latter strategy had slightly lower mean lifetime costs, saving $8.9 €$ compared to the 7-d-Holter. In the base-case scenario this resulted in additional costs per QALY gained of 5,354 €/QALY for the 7-d-Holter compared to the TTE/7-d-Holter.

In a cohort of 10,000 patients with acute cerebral ischemia, the 7-d-Holter detected 710 more cases of PAF than the 24-h-Holter; this resulted in a gain of 7.85 QALYs, or 82 more cases than TTE/7-d-Holter, resulting in 0.14 QALYs gained. Over the patients' lifetime, the 7-dHolter prevented 155 IS compared to the 24-h-Holter but oral anticoagulation caused an additional $26 \mathrm{ICH}$ (7-dHolter vs. TTE/7-d-Holter: IS: -3 ; ICH: +5).

Sensitivity analysis

Examining the key model input parameters over a wide range demonstrated that the 7 -d-Holter was cost-effective or dominant in most scenarios when compared to the 24-hHolter (Fig. 3). A variation of stroke severity of recurrent IS of ASS- or OAC-treated patients influenced the incremental cost per QALY, but never exceeded 3,022 € per QALY gained. A $10 \%$ increase in the annual risk of recurrent stroke in PAF-positive patients treated with ASS led to the dominance of the 7-d-Holter over the 24-hHolter, while a $10 \%$ reduction resulted in an ICER of $1,131 € / \mathrm{QALY}$.

Two-way sensitivity analysis investigating the annual recurrence of IS and ICH yielded an ICER of 15,145 €/ QALY comparing the use of a 7-d-Holter to a 24-h-Holter when both event rates were increased by $20 \%$; a decrease of $10 \%$ demonstrated the dominance of the 7-d-Holter (Table 4).

Variation in costs had the most influence on changes in the ICER; a $10 \%$ increase in post-acute costs for patients 
Table 4 Projected costs and QALYs for patients after ischemic stroke or TIA under base-case conditions and by varying risk of ischemic/ hemorrhagic stroke

\begin{tabular}{|c|c|c|c|c|c|c|}
\hline $\begin{array}{l}\text { Rate of IS and ICH with } \\
\text { warfarin (\% per year) }\end{array}$ & ECG setting & Cost $(€)$ & $\begin{array}{l}\text { Incremental } \\
\text { cost }(€)\end{array}$ & QALYs & $\begin{array}{l}\text { Incremental effect } \\
\text { (QALYs) }\end{array}$ & $\begin{array}{l}\text { ICER } \\
(€ \text { per QALY) }\end{array}$ \\
\hline \multirow[t]{3}{*}{ IS: $2.72 \%$, ICH: $1.15 \%$} & TTE / 7-d-Holter & $32,854.4$ & - & 3.846 & - & Reference \\
\hline & 7-d-Holter & $32,860.5$ & 6.1 & 3.848 & 0.0020 & 2978.37 \\
\hline & 24-h-Holter & $32,895.9$ & 35.4 & 3.835 & -0.0135 & Dominated \\
\hline IS: $3.02 \%$, ICH: $1.28 \%$ & TTE / 7-d-Holter & $32,886.9$ & - & 3.842 & & Reference \\
\hline \multirow[t]{2}{*}{ Base case } & 7-d-Holter & $32,895.8$ & 8.9 & 3.844 & 0.0017 & $5,353.92$ \\
\hline & 24-h-Holter & $32,912.3$ & 16.5 & 3.833 & -0.0111 & Dominated \\
\hline \multirow[t]{3}{*}{ IS: $3.32 \%$, ICH: $1.41 \%$} & TTE / 7-d-Holter & $32,918.0$ & - & 3.838 & - & Reference \\
\hline & 24-h-Holter & $32,928.0$ & 10.0 & 3.831 & -0.0073 & Dominated \\
\hline & 7-d-Holter & $32,929.7$ & 11.7 & 3.839 & 0.0013 & $8,957.96$ \\
\hline \multirow[t]{3}{*}{ IS: $3.62 \%$, ICH: $1.54 \%$} & 24-h-Holter & $32,943.2$ & - & 3.829 & - & Reference \\
\hline & TTE/7-d-Holter & $32,948.0$ & 4.9 & 3.834 & 0.0053 & 913.25 \\
\hline & 7-d-Holter & $32,962.4$ & 14.3 & 3.835 & 0.0009 & $15,145.35$ \\
\hline
\end{tabular}

$I S$ ischemic stroke, ICH intracranial hemorrhage, TTE transthoracic echocardiography, $Q A L Y$ quality-adjusted life year, ICER incremental costeffectiveness ratio

Fig. 3 Univariate sensitivity analysis on most influential variables 7-d vs. 24-h-Holter monitoring: incremental costeffectiveness ratio (ICER). Figure 3 displays the influence of a variation of variables used in the model on the ICER of the 7-d vs. 24-h-Holter. The vertical line represents the base-case scenario. Negative ICERs imply dominance of the 7-d-Holter and positive ICERs show the maximal costs per QALY gained. $A F$ atrial fibrillation, $A S S$ aspirin, $I S$ ischemic stroke, $O A C$ oral anticoagulation, $Q A L Y$ quality-adjusted life year, TIA transient ischemic attack

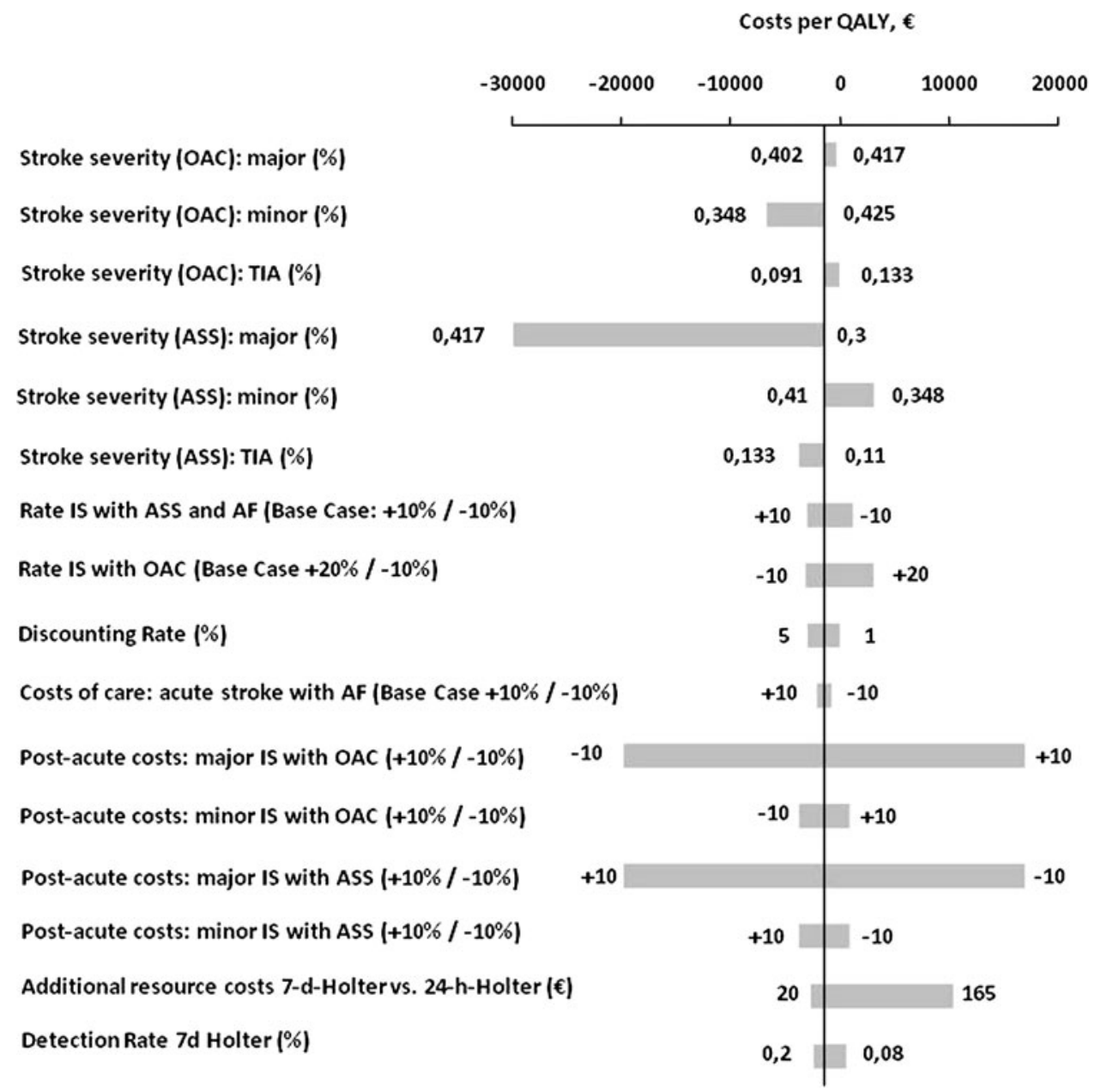


after major IS and warfarin therapy estimated an ICER of $16,911 € /$ QALY, while a $10 \%$ decrease in post-acute costs for similar patients treated with ASS yielded an ICER of $16,945 € / Q A L Y$. Extended use of Holter monitoring affected the ICER in two ways, a higher detection rate and extra costs due to the additional use of personnel and material resources. We varied the prevalence of PAF detected by 7-d-Holter from 8 to $20 \%$, yielding an ICER of $527 € /$ QALY at $8 \%$. Higher detection rates of up to $20 \%$ enhanced the dominance of 7-d-Holter with a threshold of $8.9 \%$ beyond which the 7-d-Holter was less expensive than the 24-h-Holter. Raising additional resource costs for 7-d-Holter to $165 €$ resulted in an ICER of $10,385 € / \mathrm{Q} A L Y$. The 7-d-Holter remained dominant up to a threshold of $50.2 €$.

With regard to test accuracy, 7-d-Holter remained costeffective when compared to the TTE/7-d-Holter in most scenarios. Beyond a negative predictive value of $98.9 \%$ for the preceding TTE, the TTE/7-d-Holter became the dominant strategy. An increase of PAF-prevalence without TTE up to $20 \%$ resulted in dominance of 7-d-Holter; a decrease of PAF-prevalence with preceding TTE resulted in an ICER 7-d-Holter vs. TTE/7-d-Holter of 19,491 €/ QALY at $21.5 \%$. Raising monitoring costs to $165 €$ increased the incremental cost-effectiveness ratio to $43,799 €$ per QALY gained because of the higher proportion of patients being examined by 7 -d-Holter.

\section{Discussion}

Our analysis demonstrated that using the 7-d-Holter instead of the standard 24-h-Holter to detect PAF in patients after cerebral ischemia is cost-effective. Given that prolonged Holter monitoring detects a higher number of new cases with PAF [35-37], the improved cost-effectiveness is attributable to the fact that these newly detected patients benefit from warfarin therapy to prevent stroke recurrence which in turns saves future costs.

Kamel and colleagues [38] previously examined the effect of an additional 7 days of outpatient cardiac monitoring vs. standard care to detect PAF after IS in the US. In this analysis, the detection rate of PAF was estimated to be $5.9 \%$ using outpatient monitoring which resulted in an incremental cost-effectiveness ratio of 13,000 \$/QALY, considerably below a threshold of 50,000 \$ per QALY usually considered cost-effective [38, 39]. A more realistic scenario, for instance, a scenario with a higher detection rate of PAF by 7-d-Holter ECG improves the cost-effectiveness to 5,090 \$/QALY gained [40], comparable to the data of our study. Instead of extrapolating trial data of noncontinuous ECG recordings to estimate the yield of 7-dHolter, we used actual observations from the Find-AF trial that offered intra-individual comparison of detection rates for 24-h, 48-h, and 7-d-Holter [7] in an unselected cohort of patients with cerebral ischemia. Furthermore, we prospectively assessed incremental costs for the performance of 7-d-Holter instead of 24-h-Holter in a subgroup of patients at the end of the FIND-AF trial, i.e., on top of the learning-curve for this method. In this respect, we believe that our analysis is based on solid and reliable data and our results are definitely supportive of the analysis by Kamel [38]. However in our base case, 7-d-Holter was not only cost-effective, but actually dominated the 24-h-Holter and remained highly cost-effective in the most unfavorable constellations on sensitivity analyses. In addition to supporting Kamel's analysis with an alternative model based on clinical data, our analysis was performed for a different healthcare system (i.e., the German).

Our model predicts mean undiscounted lifetime costs for patients after the first ever IS or TIA of about 46,000 $€$ and, therefore, slightly lower than those previously reported by Kolominsky-Rabas with 50,507 €. Compared to 7.3 years as reported by Kolominsky-Rabas, mean undiscounted life expectancy as predicted by our model ranged from 7.77 to 7.79 years [3]. These roughly similar figures give some external validation for our model.

To project IS recurrence, we used variables primarily based on values reported in the ACTIVE W trial [14]. To account for varying risks in PAF-positive and PAF-negative patients and to display the efficacy of warfarin and aspirin therapy within these cohorts, relative risks were used as reported in the literature [6, 15].

Regarding hemorrhagic complications of OAC treatment, we used the annual rate for ICH for patients with prior stroke or TIA taken from the RELY trial [18] and applied the relative risk ASS vs. OAC to project this event rate for ASS-treated patients $[15,18]$. Other hemorrhagic complications such as abdominal or gastrointestinal bleeding were not included in our analysis. Furthermore, we assumed that a detection of PAF by Holter monitoring results in a change of treatment to OAC therapy in any case, although contraindications of oral anticoagulation may be present in some cases. These points therefore give some limitation to our analyses. However, given these limitations and the fact that newer anticoagulation drugs (NOACs) have just recently emerged to the market, which may even further reduce stroke recurrence in patients with AF with a similar or even lower risk for cerebral bleedings [41], prolonged Holter monitoring might became even more cost-effective.

Of note, the use of routine TTE to rule out PAF and to selectively apply the 7-d-Holter to a subgroup did not increase the cost-effectiveness ratio, due to the false-negative patients missed in this approach. Because these $2.2 \%$ of patients would have been treated erroneously with antiplatelet therapy only, they would have had a higher risk 
of dying from recurrent events and, therefore, a reduction in cumulative quality-adjusted life expectancy. In sensitivity analyses, the TTE/7-d-Holter became the dominant strategy beyond a negative predictive value of $98.9 \%$. It should be noted that both false-negative patients in FindAF only had one very short episode (about 40-45 s) of PAF on the 7-d-Holter. Because some might argue that PAF has only been shown to increase the risk of thromboembolism when episodes of at least 5-6 min have been documented, interpretation of our results would then have to be modified, as TTE would preselect with $100 \%$ negative predictive value, making the TTE/7-d-Holter the dominant diagnostic strategy.

\section{Conclusions}

The use of a 7-d-Holter as opposed to a standard 24-hHolter in patients with cerebral ischemia is cost-effective across a wide range of variation of key variables and model input data.

Conflict of interest Research Grant: Rolf Wachter is a principal investigator (local) of the CRYSTAL-AF study, sponsored by Medtronic $(>\$ 10 \mathrm{k})$. Speakers' Bureau: Rolf Wachter has received payment for speakers' bureau appointments by Medtronic $(<\$ 10 \mathrm{k})$. Research Grant: for the Ex-DHF study ( $>\$ 10$ k). Speakers' Bureau: Novartis, Pfizer, Servier, BG Medicine, Berlin Chemie AG $(<\$ 10 \mathrm{k})$. The remaining all other authors have no conflicts of interest.

Open Access This article is distributed under the terms of the Creative Commons Attribution License which permits any use, distribution, and reproduction in any medium, provided the original author(s) and the source are credited.

\section{References}

1. Evers SM, Struijs JN, Ament AJ, van Genugten ML, Jager JH, van den Bos GA (2004) International comparison of stroke cost studies. Stroke 35(5):1209-1215. doi:10.1161/01.STR.00001258 60.48180 .48

2. Saka O, McGuire A, Wolfe C (2009) Cost of stroke in the United Kingdom. Age Ageing 38(1):27-32. doi:10.1093/ageing/afn281

3. Kolominsky-Rabas PL, Heuschmann PU, Marschall D, Emmert M, Baltzer N, Neundorfer B, Schoffski O, Krobot KJ (2006) Lifetime cost of ischemic stroke in Germany: results and national projections from a population-based stroke registry: the Erlangen stroke project. Stroke 37(5):1179-1183. doi:10.1161/01.STR. 0000217450.21310 .90

4. You JJ, Singer DE, Howard PA, Lane DA, Eckman MH, Fang MC, Hylek EM, Schulman S, Go AS, Hughes M, Spencer FA, Manning WJ, Halperin JL, Lip GY (2012) Antithrombotic therapy for atrial fibrillation: antithrombotic therapy and prevention of thrombosis, 9th ed: American College of Chest Physicians Evidence-Based Clinical Practice Guidelines. Chest 141(2 Suppl):e531S-e575S. doi:10.1378/chest.11-2304

5. Grau AJ, Weimar C, Buggle F, Heinrich A, Goertler M, Neumaier S, Glahn J, Brandt T, Hacke W, Diener HC (2001) Risk factors, outcome, and treatment in subtypes of ischemic stroke: the German stroke data bank. Stroke 32(11):2559-2566

6. Wolf PA, Abbott RD, Kannel WB (1991) Atrial fibrillation as an independent risk factor for stroke: the Framingham Study. Stroke 22(8):983-988

7. Stahrenberg R, Weber-Kruger M, Seegers J, Edelmann F, Lahno R, Haase B, Mende M, Wohlfahrt J, Kermer P, Vollmann D, Hasenfuss G, Groschel K, Wachter R (2010) Enhanced detection of paroxysmal atrial fibrillation by early and prolonged continuous holter monitoring in patients with cerebral ischemia presenting in sinus rhythm. Stroke 41(12):2884-2888. doi:10.1161/ STROKEAHA. 110.591958

8. Crystal E, Connolly SJ (2004) Role of oral anticoagulation in management of atrial fibrillation. Heart 90(7):813-817. doi:10. 1136/hrt.2003.02164290/7/813

9. Hart RG, Halperin JL, Pearce LA, Anderson DC, Kronmal RA, McBride R, Nasco E, Sherman DG, Talbert RL, Marler JR (2003) Lessons from the stroke prevention in atrial fibrillation trials. Ann Intern Med 138(10):831-838. doi:200305200-00011

10. Hart RG, Pearce LA, Aguilar MI (2007) Meta-analysis: antithrombotic therapy to prevent stroke in patients who have nonvalvular atrial fibrillation. Ann Intern Med 146(12):857-867. doi:146/12/857

11. Stahrenberg R, Edelmann F, Haase B, Lahno R, Seegers J, Weber-Kruger M, Mende M, Wohlfahrt J, Kermer P, Vollmann D, Hasenfuss G, Groschel K, Wachter R (2011) Transthoracic echocardiography to rule out paroxysmal atrial fibrillation as a cause of stroke or transient ischemic attack. Stroke 42:3643-3645

12. Sonnenberg FA, Beck JR (1993) Markov models in medical decision making: a practical guide. Med Decis Making 13(4): 322-338

13. Camm AJ, Lip GY, De Caterina R, Savelieva I, Atar D, Hohnloser SH, Hindricks G, Kirchhof P, Bax JJ, Baumgartner H, Ceconi C, Dean V, Deaton C, Fagard R, Funck-Brentano C, Hasdai D, Hoes A, Knuuti J, Kolh P, McDonagh T, Moulin C, Popescu BA, Reiner Z, Sechtem U, Sirnes PA, Tendera M, Torbicki A, Vahanian A, Windecker S, Vardas P, Al-Attar N, Alfieri O, Angelini A, Blomstrom-Lundqvist C, Colonna P, De Sutter J, Ernst S, Goette A, Gorenek B, Hatala R, Heidbuchel H, Heldal M, Kristensen SD, Le Heuzey JY, Mavrakis H, Mont L, Filardi PP, Ponikowski P, Prendergast B, Rutten FH, Schotten U, Van Gelder IC, Verheugt FW (2012) 2012 focused update of the ESC guidelines for the management of atrial fibrillation: an update of the 2010 ESC Guidelines for the management of atrial fibrillation * Developed with the special contribution of the European Heart Rhythm Association. Eur Heart J. doi:10.1093/ eurheartj/ehs 253

14. Connolly S, Pogue J, Hart R, Pfeffer M, Hohnloser S, Chrolavicius S, Yusuf S (2006) Clopidogrel plus aspirin versus oral anticoagulation for atrial fibrillation in the Atrial fibrillation Clopidogrel Trial with Irbesartan for prevention of Vascular Events (ACTIVE W): a randomised controlled trial. Lancet 367(9526):1903-1912. doi:10.1016/S0140-6736(06)68845-4

15. van Walraven C, Hart RG, Singer DE, Laupacis A, Connolly S, Petersen P, Koudstaal PJ, Chang Y, Hellemons B (2002) Oral anticoagulants vs aspirin in nonvalvular atrial fibrillation: an individual patient meta-analysis. JAMA 288(19):2441-2448 pii: jec20007

16. Sullivan PW, Arant TW, Ellis SL, Ulrich H (2006) The cost effectiveness of anticoagulation management services for patients with atrial fibrillation and at high risk of stroke in the US. Pharmacoeconomics 24(10):1021-1033 pii: 24109

17. O'Brien CL, Gage BF (2005) Costs and effectiveness of ximelagatran for stroke prophylaxis in chronic atrial fibrillation. JAMA 293(6):699-706. doi:10.1001/jama.293.6.699 
18. Diener HC, Connolly SJ, Ezekowitz MD, Wallentin L, Reilly PA, Yang S, Xavier D, Di Pasquale G, Yusuf S (2010) Dabigatran compared with warfarin in patients with atrial fibrillation and previous transient ischaemic attack or stroke: a subgroup analysis of the RE-LY trial. Lancet Neurol 9(12):1157-1163. doi:10.1016/ S1474-4422(10)70274-X

19. Ariesen MJ, Claus SP, Rinkel GJ, Algra A (2003) Risk factors for intracerebral hemorrhage in the general population: a systematic review. Stroke 34(8):2060-2065. doi:10.1161/01.STR.0000080678. 09344.8D

20. Hart RG, Boop BS, Anderson DC (1995) Oral anticoagulants and intracranial hemorrhage facts and hypotheses. Stroke 26(8): 1471-1477

21. Chambers MG, Koch P, Hutton J (2002) Development of a decision-analytic model of stroke care in the United States and Europe. Value Health 5(2):82-97. doi:10.1046/j.1524-4733.2002. 52011.x

22. Briggs A, Sculpher M (1998) An introduction to Markov modelling for economic evaluation. Pharmacoeconomics 13(4): 397-409

23. Landesweite Basisfallwerte (2013) Verband der Ersatzkassen e. V. http://wwwvdekcom/vertragspartner/Krankenhaeuser/DRG/ landesbasisfallwerte/2_lbfw_2005_2011_epdf. Accessed 10 June 2013

24. Begleitforschung gem $\S 17 b$ Abs. 8 KHG (2013) InEK-Institut für das Entgeltsystem im Krankenhaus. http://www.g-drg.de/cms/ Begleitforschung_gem._17b_Abs._8_KHG. Accessed 13 June 2013

25. Schilling M, Kiefer R, Busse O (2013) Kodierleitfaden Schlaganfall der DSG und DGN 2011. http://www.idrg.de/uploads/ media/Kodierleitfaden_DSG_DGN_2011_Schlaganfall.pdf. Accessed 14 June 2013

26. Webgrouper DRG Research Group Medizinisches Management (2013) website: Universitätsklinikum Münster. http://drg.unimuenster.de/index.php. Accessed 14 June, 2013

27. Brüggenjürgen B, Rupprecht $\mathrm{H}$, Willich S, Spannagl M, Ehlken B, Smala A, Berger K, Diener H (2005) Cost of atherothrombotic diseases-myocardial infarction, ischaemic stroke and peripheral arterial occlusive disease-in Germany. J Public Health $13: 216-224$

28. Hein L (2010) Antikoagulantien und Thrombozytenaggregationshemmer. In: Arzneiverordnungs-Report 2010: Aktuelle Daten. Kosten, Trends Und Kommentare. Springer, Heidelberg, pp 409-424

29. Ärztegehälter im Vergleich (2013) website: Vereinigung der kommunalen Arbeitgeberverbände. http://wwwvkade/media/exe/ 59/5e98017fbd2136876f289d29949ebc35/110908_vergleichaerzeteentgeltepdf. Accessed 10 June 2013

30. Tauch J (2003) Personalbedarfsermittlung im Krankenhaus-Personalbedarfsermittlung im DRG-Zeitalter, 5th edn., edn. Gütersloher Organisationsberatung, Gütersloh

31. Gage BF, Cardinalli AB, Albers GW, Owens DK (1995) Costeffectiveness of warfarin and aspirin for prophylaxis of stroke in patients with nonvalvular atrial fibrillation. JAMA 274(23): 1839-1845
32. Tengs TO, Lin TH (2003) A meta-analysis of quality-of-life estimates for stroke. Pharmacoeconomics 21(3):191-200 pii: 210304

33. Haacke C, Althaus A, Spottke A, Siebert U, Back T, Dodel R (2006) Long-term outcome after stroke: evaluating health-related quality of life using utility measurements. Stroke 37(1):193-198. doi:10.1161/01.STR.0000196990.69412.fb

34. Christensen MC, Mayer S, Ferran JM (2009) Quality of life after intracerebral hemorrhage: results of the factor seven for acute hemorrhagic stroke (FAST) trial. Stroke 40(5):1677-1682. doi:10.1161/STROKEAHA.108.538967

35. Liao J, Khalid Z, Scallan C, Morillo C, O’Donnell M (2007) Noninvasive cardiac monitoring for detecting paroxysmal atrial fibrillation or flutter after acute ischemic stroke: a systematic review. Stroke 38(11):2935-2940. doi:10.1161/STROKEAHA. 106.478685

36. Barthelemy JC, Feasson-Gerard S, Garnier P, Gaspoz JM, Da Costa A, Michel D, Roche F (2003) Automatic cardiac event recorders reveal paroxysmal atrial fibrillation after unexplained strokes or transient ischemic attacks. Ann Noninvasive Electrocardiol 8(3):194-199 pii:08305

37. Jabaudon D, Sztajzel J, Sievert K, Landis T, Sztajzel R (2004) Usefulness of ambulatory 7-day ECG monitoring for the detection of atrial fibrillation and flutter after acute stroke and transient ischemic attack. Stroke 35(7):1647-1651. doi:10.1161/01.STR. 0000131269.69502.d901.STR.0000131269.69502.d9

38. Kamel H, Hegde M, Johnson DR, Gage BF, Johnston SC (2010) Cost-effectiveness of outpatient cardiac monitoring to detect atrial fibrillation after ischemic stroke. Stroke 41(7):1514-1520. doi:10.1161/STROKEAHA.110.582437

39. Gold JS, Russel LB, Weinstein MC (1996) Cost-effectiveness in Health and Medicine. Oxford University Press, New York

40. Wachter R, Stahrenberg R, Groschel K (2011) Letter by Wachter et al regarding article "Cost-effectiveness of outpatient cardiac monitoring to detect atrial fibrillation after ischemic stroke". Stroke 42(3):e36-e37. doi:10.1161/STROKEAHA.110.604173 Author reply

41. Connolly SJ, Ezekowitz MD, Yusuf S, Eikelboom J, Oldgren J, Parekh A, Pogue J, Reilly PA, Themeles E, Varrone J, Wang S, Alings M, Xavier D, Zhu J, Diaz R, Lewis BS, Darius H, Diener HC, Joyner CD, Wallentin L (2009) Dabigatran versus warfarin in patients with atrial fibrillation. N Engl J Med 361(12): 1139-1151. doi:10.1056/NEJMoa0905561

42. Bruggenjurgen B, Rossnagel K, Roll S, Andersson FL, Selim D, Muller-Nordhorn J, Nolte $\mathrm{CH}$, Jungehulsing GJ, Villringer A, Willich SN (2007) The impact of atrial fibrillation on the cost of stroke: the berlin acute stroke study. Value Health 10(2): 137-143. doi:10.1111/j.1524-4733.2006.00160.x

43. Weimar C, Weber C, Wagner M, Busse O, Haberl RL, Lauterbach KW, Diener HC (2003) Management patterns and health care use after intracerebral hemorrhage. a cost-of-illness study from a societal perspective in Germany. Cerebrovasc Dis 15(1-2):29-36 pii:ced15029 